\title{
Cellular Mechanisms of Saline Extract of Alligator Pepper (Zingiberaceae Aframomum melegueta) for Specific Protection against Preeclampsia
}

\author{
Ute Inegbenebor ${ }^{1, *}$ and Maureen Ebomoyi ${ }^{2}$ \\ ${ }^{1}$ Department of Physiology, Faculty of Basic Medical Sciences, College of Medicine, Ambrose Alli University, \\ Ekpoma, Nigeria \\ ${ }^{2}$ Department of Physiology, School of Basic Medical Sciences, College of Medical Sciences, University of \\ Benin, Benin City, Nigeria
}

\begin{abstract}
Preeclampsia is a clinical syndrome defined as the new onset of hypertension and proteinuria during the second half of pregnancy. Though it is easily diagnosed clinically, affected persons must book in a health service facility for the diagnosis to be made. Furthermore regular screening is necessary during several antenatal visits and skilled attendant's supervised labor before diagnosis can be made. Predictive tests are not yet well developed and not readily available in developing countries and medically underserved areas where they are needed most. There is therefore a need for specific protection against preeclampsia to be developed. This will ensure that all women are protected even when they choose not to visit an antenatal clinic. Specific protection is potentially capable of preventing preeclampsia in $5 \%$ to $7 \%$ of pregnant women, the proportion of pregnant women that are affected by preeclampsia worldwide. This article builds on a previous article on the study of the cellular mechanisms underlying gestational weight gain and litter weight reduction effect of aqueous extract of Alligator pepper and attempts to analyze how the anti-hyperinsulinemic property of the constituents of Alligator pepper in that study can also prevent preeclampsia and suggests the use of some of the constituents of alligator pepper as specific protection (vaccine) for the prevention of preeclampsia.
\end{abstract}

Keywords: Cellular Mechanisms, Alligator pepper, Preeclampsia, Specific protection.

\section{INTRODUCTION}

Preeclampsia is a clinical syndrome defined as the new onset of hypertension and proteinuria during the second half of pregnancy [1]. Both hypertension and proteinuria implicate the endothelium as the target of the disease [2]. Common risk factors include first pregnancy, new paternity, teenage pregnancy, pregnancy in the forties, prolonged interval between pregnancies, diabetes mellitus in pregnancy, and chronic vascular hypertensive disease [3]. Common complications include stroke, placental abruption, seizures, low fetal birth weight and hemorrhage. Once preeclampsia is present in a pregnancy, there is no definitive cure other than to deliver the child and the placenta. Preeclampsia carries with it a significant risk of injury or death to both the mother and child [4].

The ability to predict preeclampsia is currently of limited benefit because, neither the development of the disorder, nor its progression from the mild to the severe spectrum of disease, can be prevented in most patients. Besides, there is no cure except delivery [5]. Up till recently there were no clinically available tests that perform well in distinguishing women who will

*Address correspondence to this author at the Department of Physiology, Faculty of Basic Medical Sciences, College of Medicine, Ambrose Alli University, Ekpoma, Nigeria; E-mail: druteinegbenebor@yahoo.com

E-ISSN: 1929-5634/14 develop preeclampsia from those who will not [6]. Researchers have now found that among pregnant women who developed preeclampsia later in pregnancy, the number of capillaries was reduced early in pregnancy-even at 20 weeks of pregnancy. Data show that using this novel, simple measure seemed to identify those women who are likely to develop preeclampsia 87 percent of the time-an improvement on the currently used screening test [7]. Repeating the test during the course of pregnancy at or after 27 weeks gestation accurately identified the condition 75 percent of the time and was less likely to include false positives - women who would not go on to develop the condition. However most of the predictive tests are not yet available in most developing countries where clinical diagnosis can only be made during antenatal screening of patients and sometimes for the first time in labor. It is therefore obvious that in medically underserved areas and places where there is low patronage of antenatal clinics, several women will develop preeclampsia and only present in labor with eclamptic fits in traditional birth attendant's homes or as unbooked patients in health care providers' clinics that are least prepared for the much needed attention that eclampsia deserves. It is therefore necessary to develop a method of preventing the development of the disease. Since there are no definite (health education and promotion) methods of averting the development of the disease and early diagnosis and treatment are only 
possible where women turn up in antenatal clinics for screening, specific protection becomes the most important tool that can be used for mass protection of women from this second leading cause of maternal mortality, worldwide behind complications of child birth itself [7].

This article is a build up on a controlled cross sectional intervention study to determine the cellular mechanisms underlying the gestational weight gain and litter size reduction effects of intraperitoneally injected saline extract of Alligator pepper (Zingiberaceae Aframomum meleguta) [8] described below for easy reference.

\section{RESEARCH METHODS}

We conducted a controlled cross sectional intervention study. After acclimatization for two weeks in cages, during which all rats were fed with water and grower's marsh ad libitum, 45 male and 45 female Sprague Dawley rats were allocated to cages in such a way that each cage contained one male and one female rat. They remained in these cages for three days during which they were expected to mate. Thereafter, the female rats were randomly allocated into three groups $A, B$ and $C$ with 15 female rats in each group. These three major groups were further randomly allocated into three subgroups of 5 female rats each so that the sub groups were then labeled $A_{1}$, $A_{2} A_{3} ; B_{1}, B_{2}, B_{3} ;$ and $C_{1}, C_{2}, C_{3}$.

Pregnant female rats in Group A were injected with $2 \mathrm{ml}$ of normal saline intra-peritoneally on day 4 . Pregnant female rats in groups $B$ and $C$ were injected intraperitoneally with $6.7 \mathrm{mg} / \mathrm{Kg}$ body weight and $13.3 \mathrm{mg} / \mathrm{kg}$ body weight of saline extract of Alligator Pepper respectively on day 4 in line with the doses used in an experiment on the effect of aqueous extract of Alligator pepper on gestational weight gain by Inegbenebor and colleagues in 2009 [9]. The dose of $6.7 \mathrm{mg} / \mathrm{Kg}$ body weight of Alligator pepper was christened 'low dose' Alligator pepper extract while the dose of $13.3 \mathrm{mg} / \mathrm{kg}$ body weight of Alligator pepper was christened 'high dose' Alligator pepper extract in order to distinguish between the two doses nominally and in ranking [8].

All rats in subgroups $A_{1}, B_{1}, C_{1} ; A_{2} . B_{2}, C_{2}$; and $A_{3}$, $B_{3}, C_{3}$ were euthanized by cervical dislocation on days 7, 14 and 21 respectively following chloroform anesthesia. Blood was collected by intra-ventricular aspiration and assayed for insulin levels using Insulin ELISA (Ref EIA 2935) produced by DRG Instruments $\mathrm{GmbH}$, Marburg, Germany. Pregnancy was confirmed by dissecting the uteri of the rats to reveal the embryo/fetuses in their gestational uterine cavity. Glucose levels were estimated from capillary blood from the rats' tail after a 12 hour fast using a glucometer (ACCU CHEK; Roche) on days 7, 14, and 21. Means and standard deviations were calculated for each of the subgroups and observed differences between control and experimental groups were subjected to tests of significance [8].

\section{RESULTS}

Serum fasting glucose levels were significantly higher in Alligator pepper treated rats on days 7,14 and 21. $(P=0.000,0.000 .0 .001$ on days 7,14 and 21

Table 1: Time and Dose Effect of Alligator Pepper on Serum Glucose Level in Pregnant Sprague Dawley Rats

\begin{tabular}{|c|c|c|c|c|c|c|c|}
\hline \multirow{2}{*}{\multicolumn{2}{|c|}{ Group }} & \multirow{3}{*}{$\begin{array}{c}\begin{array}{c}\text { No of } \\
\text { Rats }\end{array} \\
15\end{array}$} & \multirow{3}{*}{$\begin{array}{c}\begin{array}{c}\text { Pregnancy } \\
\text { Status }\end{array} \\
\text { Pregnant }\end{array}$} & \multirow{3}{*}{$\begin{array}{c}\begin{array}{c}\text { Dose of } \\
\text { Alligator } \\
\text { Pepper in } \\
\text { Kg/body wt }\end{array} \\
\text { Nil }\end{array}$} & \multicolumn{3}{|c|}{ Mean Blood Glucose LeveltSD mmol/l } \\
\hline & & & & & \multirow{2}{*}{$\begin{array}{c}\text { Day } 7 \\
\begin{array}{c}4.85 \pm 0.62 \\
\left(\text { Subgrp } A_{1}\right)\end{array}\end{array}$} & \multirow{2}{*}{$\begin{array}{c}\text { Day } 14 \\
\begin{array}{c}4.22 \pm 0.23 \\
\left(\text { Subgrp } A_{2}\right)\end{array}\end{array}$} & \multirow{2}{*}{$\begin{array}{c}\text { Day } 21 \\
3.69 \pm 0.16 \\
\left(\text { Subgrp } A_{3}\right)\end{array}$} \\
\hline A & Control & & & & & & \\
\hline $\mathrm{B}$ & Experimental & 15 & Pregnant & $6.7 \mathrm{mg}$ & $\begin{array}{c}6.53 \pm 0.23 \\
\left(\text { Subgrp } B_{1}\right)\end{array}$ & $\begin{array}{c}5.55 \pm 0.45 \\
\left(\text { Subgrp } B_{2}\right)\end{array}$ & $\begin{array}{c}5.03 \pm 0.55 \\
\left(\text { Subgrp } B_{3}\right)\end{array}$ \\
\hline \multicolumn{3}{|c|}{$P$-value $(A$ and $B)$} & & & $0.000^{\star *}$ & $0.000^{\star *}$ & $0.001^{\star *}$ \\
\hline C & Experimental & 15 & Pregnant & $13.3 \mathrm{mg}$ & $\begin{array}{c}6.06 \pm 0.13 \\
\left(\text { Subgrp } C_{1}\right)\end{array}$ & $\begin{array}{c}5.89 \pm 0.25 \\
\left(\text { Subgrp } C_{2}\right)\end{array}$ & $\begin{array}{c}7.5 \pm 0.07 \\
\left.\text { (Subgrp } C_{3}\right)\end{array}$ \\
\hline \multicolumn{3}{|c|}{$P$ value $(A$ and $C)$} & & & $0.003^{* *}$ & $0.000^{* *}$ & $0.000^{* *}$ \\
\hline \multicolumn{3}{|c|}{$P$ value $(B$ and $C)$} & & & $0.004^{* *}$ & 0.178 & $0.000^{* *}$ \\
\hline
\end{tabular}

**Significant.

Courtesy, Inegbenebor, U and Ebomoyi. M Cellular Mechanisms of Saline Extract of Alligator Pepper (Zingiberaceae Aframomum melegueta for Specific Protection against Fetal Macrosomia Journal of Nutritional Therapeutics 2014; 3(1). 
Table 2: Time and Dose Effect of Alligator Pepper on Blood Insulin in Pregnant Sprague Dawley Rats

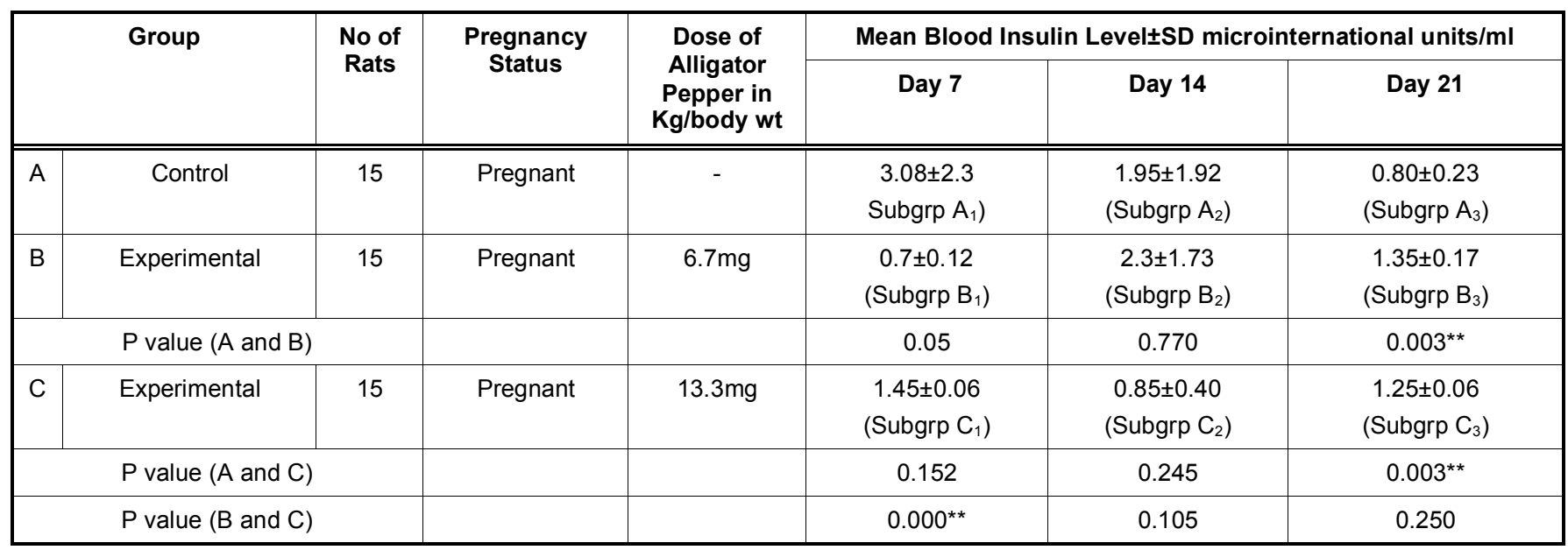

${ }^{* *}$ Significant.

Courtesy, Inegbenebor, U and Ebomoyi, M Cellular Mechanisms of Saline Extract of Alligator Pepper (Zingiberaceae Aframomum melegueta for Specific Protection against Fetal Macrosomia Journal of Nutritional Therapeutics 2014; 3(1)

respectively) Higher dose of Alligator pepper only made a significant difference in increasing serum fasting glucose level on days 7 and 21 . $(P=0.004$ and 0.000 on days 7 and 21 respectively) See Table 1 [8].

Low dose Alligator pepper treated pregnant rats had lower serum insulin levels than control groups on day 7 only while higher dose Alligator pepper treated rats had lower insulin levels days 7 and 14 see Table 2. While the extract of Alligator pepper caused a reduction in serum insulin levels, there was a significant increase in fasting blood glucose levels [8].

\section{DISCUSSION}

Insulin levels determine the utilization of nutrients in the growth and development of the mother and fetus. However, cellular resistance to insulin may amplify the effect of metabolites on the growth and development of the fetus [10]. It may also be responsible for gestational diabetes mellitus and pregnancy induced hypertension, which may be adverse to pregnancy outcome [11]. In multivariate analyses of 481 glucose tolerant obese women, increasing weight gain was associated with significantly higher rates of hypertension (OR 4.8 [95\% $\mathrm{Cl}$ for group 4 vs. group 1: 1.7-13.1]), cesarean section (3.5 [1.6-7.8]), induction of labor (3.7 [1.7-8.0]), and large-for-gestational-age infants (4.7 [2.0-11.0]) [12].

Several authors have attempted to link preeclampsia with hyperinsulinemia. In a controlled study to assess whether hyperinsulinemia is present in hypertensive disease induced by pregnancy, It was concluded that preeclampsia is associated with marked hyperinsulinemia both in the fasting state and after oral glucose ingestion, suggesting that insulin resistance may play a role in pregnancy-induced hypertension [13]. In another case control study of fasting insulin levels in normal pregnancy and pre-eclampsia patients, it was concluded that an exaggeration of the insulin resistance is seen with the resultant hyperinsulinemia in women with pregnancy complicated by preeclampsia The results of the study also showed that hyperinsulinemia was directly proportional to the severity of the disease [14]. Aside from insulin resistance, endothelial activation and low grade inflammation play an integral role in the preeclampsia/eclampsia, obesity and gestational diabetes. Insulin resistance with secondary hyperinsulinemia is suspected to be the link between hypertension and diabetes mellitus. The hypertensive effect of hyperinsulinemia is postulated to be due to weight gain as well as extracellular volume expansion. This volume expansion is thought to result from renal sodium retention caused by insulins effect on sympathetic activity [15].

In a previous study, it was found that intraperitoneally injected extract of Alligator pepper was capable of reducing gestational weight gain and litter size [9]. In an attempt to study the cellular mechanisms underlying the effects of Alligator pepper extract, it was found that saline extract of Alligator pepper depresses blood insulin level [8]. Hyperinsulinemia of pregnancy is related etiologically to the development of preeclampsia and the onset of preeclampsia is usually in the second or third trimester of pregnancy [13-15]. Since the saline extract of Alligator pepper reduced 
fasting blood insulin levels on day 7 (end of first trimester) at the dose of $6.7 \mathrm{mg} / \mathrm{Kg}$ body weight and also reduced fasting blood insulin levels on days 7 and 14 (end of first and second trimester) at a higher dose of $13.3 \mathrm{mg} / \mathrm{Kg}$ body weight, we are postulating that the saline extract of Alligator pepper can prevent the development of preeclampsia (See Table 2).

Certain sesquiterpene constituents of Alligator pepper, namely, trans-caryophyllene and alphahumulene [16] reduce the secretion of tumor necrotic factor alpha [17, 18]. Tumor Necrotic factor alpha is known to reduce glucose-stimulated insulin secretion in pancreatic beta-cells [19]. Trans-caryophyllene also modulates glucose stimulated insulin.

High insulin level causes hypertension by increasing sodium ion retention through a direct increase on the activity of the epithelial sodium channel $(\mathrm{ENaC})$, the sodium phosphate co-transporter, sodium hydrogen exchanger type III and Na-K-ATPase in the kidney [20]. Insulin also induces oxidative stress, which causes impairment of the vascular endothelium, decreased availability of nitric oxide, and therefore atherosclerosis and hypertension [21]. Insulin causes excitation of the sympathetic nervous system via a central action on the hypothalamus, where it is believed to act on the anteroventral third ventricle hypothalamic region [22]. Other researchers have found that hyperinsulinemia in normotensive humans increases sympathetic nerve activity but not arterial pressure since it also causes skeletal muscle vasodilatation. However, in the presence of insulin resistance and/or hypertension, insulin may cause exaggerated sympathetic activation or impaired vasodilatation and thus elevate arterial pressure [23]. In addition, high level of insulin as seen in insulin resistance suppresses intracellular magnesium. The suppressed intracellular magnesium concentration may result in defective tyrosine kinase activity and modify insulin sensitivity by influencing receptor activity after binding or by influencing intracellular signaling and processing.

Intracellular magnesium deficiency may affect the development of insulin resistance and alter the glucose entry into the cell. Magnesium is therefore required for both proper glucose utilization and insulin signaling. Metabolic alterations in cellular magnesium, which may play the role of a second messenger for insulin action, contribute to insulin resistance [24]. The reduced intracellular magnesium causes an increase in vascular tone and therefore hypertension [25]. Low insulin levels as produced by Alligator pepper extract may therefore be capable of increasing intracellular magnesium and reducing vascular tone in pregnancy. This effect may therefore be useful in the prevention of preeclampsia and therefore eclampsia. Reduction of insulin levels by extract of Alligator pepper may also preserve vascular endothelium and the nitric oxide it secretes [21] and therefore prevent pregnancy induced hypertension and eclampsia.

\section{CONCLUSION}

We conclude that intraperitoneal injection of saline extract of Alligator pepper may prevent preeclampsia by preventing hyper-insulinemia as has been demonstrated in this study using the pregnant Sprague Dawley rats' model.

\section{RECOMMENDATION}

In order to provide mass specific protection for the illiterate, ignorant and poverty stricken women who live in medically underserved areas, we suggest that a vaccine should be developed from Alligator pepper that can act as a specific protection for preeclampsia, a precursor of eclampsia that is the second highest cause of maternal mortality [7].

\section{FUNDING}

None.

\section{CONFLICT OF INTEREST}

None declared.

\section{AUTHOR'S CONTRIBUTION}

U.I carried out the research and also wrote the article under the supervision of M.E.

\section{ACKNOWLEDGEMENT}

I wish to acknowledge Mr. Uwaifo Akpamu of Anthonio Research Center, Ekpoma and Mr. A. E. Aigbiremolen of the Department of Pharmacology, Ambrose Alli Unioversity, Ekpoma, Nigeria for their assistance in the laboratory.

\section{REFERENCES}

[1] ACOG Practice Bulletin Committee. Diagnosis and management of preeclampsia and eclampsia. Obstet Gynecol 2002; 99: 159-16.

http://dx.doi.org/10.1016/S0029-7844(01)01747-1

[2] Powe, CE, Levine, RJ, Karumanchi SA. Preeclampsia, a Disease of the Maternal Endothelium: The Role of 
Antiangiogenic Factors and Implications for Later Cardiovascular Disease Circulation 2011; 123: 2856-69. http://dx.doi.org/10.1161/CIRCULATIONAHA.109.853127

[3] http://www.mayoclinic.org/diseases-conditions/preeclampsia/ basics/risk-factors/con-20031644. Accessed on 23-03-2014.

[4] Alladin AA, Harrison M. Preeclampsia: Systemic Endothelial Damage Leading to Increased Activation of The Blood Coagulation Cascade. J Biotech Res 2012; 4: 26-43.

[5] Angeli F, Angeli E, Reboldi G, Verdecchia P. Hypertensive disorders during pregnancy: clinical applicability of risk prediction models. J Hypertens 2011; 29: 2320. http://dx.doi.org/10.1097/HJH.0b013e32834d6ed7

[6] Norwtz ER. Prediction of Preeclampsia Based on Risk Factors http: //www.uptodate.com/contents/prediction-ofpreeclampsia Accessed on 23-03-2014.

[7] American College of Cardiology "Novel marker helps identify preeclampsia risk in pregnancy." ScienceDaily 2013. www.sciencedaily.com/releases2013/03/13030712244225.ht $\mathrm{m}$

[8] Inegbenebor U, Ebomoyi M. Cellular Mechanisms of Saline Extract of Alligator Pepper (Zingiberaceae Aframomum melegueta for Specific Protection against Fetal Macrosomia. J Nutr Therapeut 2014; 3(1).

[9] Inegbenebor U, Ebomoyi MI, Onyia KA, Amadi K, Aigbiremolen AE. Effect of Alligator Pepper (Zingaberaciae Aframomum meligueta) on Gestational Weight Gain. In Nigerian J Physiol Sci 2009; 24(2): 165-69. PMID: 20234759

[10] Sardesai V. Nutritional aspects of Pregnancy and Lactation. Introduction to Clinical Nutrition, Third Edition. CRC Press 2011; 283-285

[11] Mastrogiannis DS, Spiliopoulos M, Mulla W, Homko CJ. Insulin resistance: The possible link between gestational diabetes mellitus and hypertensive disorders of pregnancy 2009; 9(4): 296-302.

[12] Jensen DM, Ovesen P, Beck-Nielsen H, GestMølstedPedersen L, Sørensen B, Vinter C, Damm P. Gestational weight gain and pregnancy outcome in 481 obese glucose tolerant women. Diabetes Care 2005; 28(9): 2118-22. http://dx.doi.org/10.2337/diabetes care.28.9.2118

[13] Martinez AE, Gonzalez OM, Quiñones GA, Ferrannini E. Hyperinsulinemia in glucose-tolerant women with preeclampsia. A controlled study. Am J Hypertens 1996; (6): 610-4 http://dx.doi.org/10.1016/0895-7061(95)00448-3

[14] Mariyappa SR. A case control study of Fasting insulin levels in normal pregnancy and preeclampsia patients being a Dissertation Submitted to the Rajiv Gandhi University Of Health Sciences, Bangalore, Karnataka in partial fulfillment of the requirements for the degree of Master of Surgery in Obstetrics and Gynecology 2013; 1-61.
$[15$

Conway D, Ed. Insulin Resistance: the underlying common pathological association between Obesity, Diabetes and Hypertension Pregnancy in the Obese Woman: Clinical Management Blackwell Publishing Limited 2011; 1-30.

[16] Ajaiyeoba EO, Ekundayo OE. Essential oil constituents of Aframomum melegueta (Roscoe) K. Schum. seeds (alligator pepper) from Nigeria. Flavour and Fragrance Journal 1999; 14(2): 109-11.

http://dx.doi.org/10.1002/(SICI)10991026(199903/04)14:2<109::AID-FFJ775>3.0.CO;2-M

[17] Fernandes ES, Passos GF, Medeiros R, da Cunha FM Ferreira J, Campos MM, Pianowski LF, Calixto JB. Antiinflammatory effects of compounds alpha-humulene and (-)trans-caryophyllene isolated from the essential oil of Cordia verbenacea. Eur J Pharmacol 2007; 569(3): 228-36. http://dx.doi.org/10.1016/j.ejphar.2007.04.059

[18] Medeiros R, Passos GF, Vitor CE, Koepp J, Mazzuco TL, Pianowski LF, Campos M, Calixto JB. Effect of two active compounds obtained from the essential oil of Cordia verbenacea on the acute inflammatory responses elicited by LPS in the rat paw. Br J Pharmacol 2007; 151(5): 618-27. http://dx.doi.org/10.1038/sj.bjp.0707270

[19] Zhang S, Kim KH. TNF-alpha inhibits glucose-induced insulin secretion in a pancreatic beta-cell line (INS-1). FEBS Lett 1995; 377(2): 237-39. http://dx.doi.org/10.1016/0014-5793(95)01272-9

[20] Tiwari T, Riazi S, Ecelbarger CA. Insulin's impact on renal sodium transport and blood pressure in health, obesity, and diabetes.American Journal of Physiology - Renal Physiology 2007; 293(F974-F984). http://dx.doi.org/10.1152/ajprenal.00149.2007

[21] Virdis A, Neves MF, Duranti E, Bernini G, Taddei S Microvascular endothelial dysfunction in obesity and hypertension. Curr Pharm Des 2013; 19(13): 2382-9. http://dx.doi.org/10.2174/1381612811319130006

[22] Muntzel MS, Anderson EA, Johnson K, Mark AL. Mechanisms of insulin action on sympathetic nerve activity. Clin Exp Hypertens 1995; 17(1-2): 39-50. http://dx.doi.org/10.3109/10641969509087053

[23] Anderson EA, Balon TW, Hoffman RP, Sinkey CA, Mark AL. Insulin increases sympathetic activity but not blood pressure in borderline hypertensive humans. Hypertension 1992; 19(6 Pt 2): 621-27. http://dx.doi.org/10.1161/01.HYP.19.6.621

[24] Takaya J, Higashino H, Kobayashi Y. Intracellular magnesium and insulin resistance. Magnesium Res 2004; 17(2): 126-36.

[25] Paolisso G, Barbagallo M. Hypertension, diabetes mellitus, and insulin resistance: the role of intracellular magnesium. Am J Hypertens 1997; 10(3): 346-55. http://dx.doi.org/10.1016/S0895-7061(96)00342-1 